\title{
Reliability and Validity of EBM Resources of Pharmacy Research Questionnaire in Saudi Arabia
}

\author{
Yousef Ahmed Alomi*, (D Critical \\ care clinical pharmacists, TPN Clinical \\ Pharmacist, Freelancer Business Planner, \\ Content Editor and Data Analyst, Riyadh, \\ Saudi Arabia. \\ Ebtissam Mohammad Badawoud, B. Sc. \\ Pharm, MSc, Pharmacist, Alnoor Specialist \\ Hospital, Makkah, Saudi Arabia.
}

\section{Correspondence: \\ Dr. Yousef Ahmed Alomi, BSc. Pharm, MSc. Clin Pharm, BCPS, BCNSP, DiBA, CDE, Critical care clinical pharmacists, TPN clinical pharmacist, Freelancer Business Planner, Content Editor and Data Analyst, P.O.BOX 100, Riyadh 11392, Riyadh, Saudi Arabia.}

Phone no: +966504417712

E-mail: yalomi@gmail.com
Copyright: ๑ the author(s),publisher and licensee Pharmacology, Toxicology and Biomedical Reports. This is an open-access article distributed under the terms of the Creative Commons Attribution NonCommercial License, which permits unrestricted non-commercial use, distribution, and reproduction in any medium, provided the original work is properly cited.

This is an open access article distributed under the terms of the Creative Commons Attribution-NonCommercial-ShareAlike 4.0 License

Access this article online

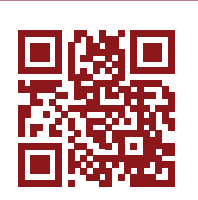

www.ptbreports.org

DOI:

10.5530/PTB.2020.6.5

\begin{abstract}
Objectives: To declare reliability and validity of EBM Resources Knowledge used for Pharmacy Research Survey in Saudi Arabia. Methods: It is a cross-section survey developed by the authors and the researcher team. It's based on the updated literature, national and international accreditation standards organizations. The internal consistency reliability through, inter-rater reliability, item-item coloration, item-total coloration, split half reliability (Gutmann's $\lambda 6$ ) and McDonald's $\omega$, Cronbach alpha. The validity contained of face content validity, construct validity through exploratory factorial analysis and confirmatory factor analysis. All analysis had been done through Statistical Package of Social Sciences (SPSS), Statistical Package of Social Sciences-Analysis of Moment Structures (SPSS-Amos) and Jeffrey's Amazing Statistics Program (JASP). Results: A total of 209 pharmacists responded. The majority of responders were Saudi 185 (88.52\%). The responders were males $108(61.77 \%)$ and females $101(48.33 \%)$. The three tests had been done with reliability of 16 questions. The completed number of responders (200) (mean \pm SD) was $3.179 \pm 0.436$, McDonald's $\omega$, Cronbach alpha and Gutmann's 16 were $0.967,0.966$ and 0.976 , respectively, inter-item coloration was 0.719 , the item-total coloration $>0.7$, McDonald's $\omega$, Cronbach alpha and Gutmann's $\lambda 6$ value if deleted was $>0.97$. By using Exploratory Factor Analysis (EFA), the Kaiser-Meyer-Olkin Measure of sampling adequacy was 0.941 and Bartlett's test of sphericity with approximate chi-square was $<0.001$. The commonalities extraction for all questions were $>0.58$, the related components were one of the rotated component matrix $>0.59$ of all 16 questions in component 1 as suggested. They were established by confirmatory with statistically significant $(p<0.001)$ of the factor model, by factor analysis, by scree plot, pathway analysis and fit with the original survey. The confirmatory factor index was 0.862 , Tucker-Lewis Index (TLI) was 0.841 , Goodness of fit index (GFI) was 0.906 and Expected cross validation index (ECVI) was 3.270. The collinearity of 16 questions was the auto-correlation was 0.066 with not statically significant $(p=0.317)$. The majority of 16 questions had Enjuone value close to number 1, while 3 questions only had condition index more than 30. All of the 16 questions had The Variance inflation factor (VIF) less than 10 and had tolerance more than 0.1. Conclusion: The pharmacist survey knowledge of evidence-based medicine resources for pharmacy practice and distributed the Kingdom of Saudi Arabia had high reliability and validity scale level. The pharmacy researcher can utilized surveys with an adequate number of sample sizes with further research in Saudi Arabia.
\end{abstract}

Key words: Reliability, Validity, EBM, Resources, Knowledge, Pharmacy, Research, Saudi Arabia.

\section{INTRODUCTION}

Over the past years, pharmacy or healthcare resources developed from textbooks and journal paper types to primary or secondary and tertiary references like newly type of resources called evidence-based medicine resources. It's based on the best and high quality of method research design with meta-analysis of randomized controlled studies. The EBM resources one great to validate studies to accept or reject the pharmacy or medical recommendation. As a result, several types of research were used methods to validate their tool of collecting the data. Two concepts the researcher implemented for observations cross-sectional researches with very much used for survey distributed to target sample. The first concept called reliability "which defined as scale or test is reliable to the extent that repeat measurements made by it under constant conditions will give the same result". ${ }^{1}$ There were several types of reliability, for instance, test-retest reliability, inter-rater reliability and the internal consistency reliability through by using biostatistical analysis. The reliability text demands to assure the accuracy of the data with got off an excellent survey that can be repeated several times with the same accuracy. The second concept used in the research called validity, "which defined as the degree to which the researcher has measured what he has set out to measure". The validation procedures had various types, for instance, content and construct validity, which commonly used in practice. The construct validity needs particular training in the biostatistical software program to implement the tools. The validation process measured as a quality management tool used in the research and keep in direct specific goal without deviation, the high validity survey correlated with the question and each group of questions targets specific aim of the research.

The scientific research contained of several steps that including revision of literature. The literature with substantial evidence like meta-analysis trial and randomized controlled study to low strength evidence with case report or experience. Multiple types of resources started from evidence-based medical (EBM) references and general searching 
engines. The literature review with an emphasis of EMB resources are very perilous in the pharmacy research and high demand for skills of searching all types of references. ${ }^{2}$ Various studies discussed EBM knowledge or perception with validated survey. ${ }^{3}$ The authors and his team have done one survey about EBM as general concept or resources of pharmacy with brief reliability and validity. ${ }^{4}$ Besides, various publications released for undergraduate or post-graduate research without detail evidence or simple reliability and validity procedures. ${ }^{5,6}$ There were some problems with pharmacy or medical researches with an emphasis on reliability and validity sections. ${ }^{7,8}$ The author not away from any study about the reliability or validity survey of EBM used in pharmacy or medical research, however, some literature discussed about pharmacist perception of EBM including resources by using used previous validated survey. ${ }^{69-12}$ The aim of the current study is to discover the reliability and validity of the survey for EBM used in pharmaceutical research in the Kingdom of Saudi Arabia.

\section{METHODS}

\section{Survey Development}

It is a cross-section survey developed by the authors and hit the researcher team. It's based on the updated literature, national and international accreditation standards organizations. ${ }^{13-16}$ The survey entailed of two parts, the first section about demographic data of responders including genders, nationality with dichotomous data and age with ordinal data. The rest of the data as ordinal information that's including the responder's qualifications, background education, the board of pharmaceutical certificate and the current job and experience. The other section of demographic information was hospital data with ordinal data and included hospital bed capacity based on the ministry of health classification; the university updated hospital accreditation status from national and international accreditation institutions. The second part of the survey about patient satisfaction of pharmacy services. The section divided into several domains and each domain had several questions. The answers of the domains were likely with 1 (I do not need this knowledge), 2 (I do not have knowledge), 3 (Weak knowledge), 4 (Incomplete knowledge) and 5 (Complete knowledge). A pilot study was done through the authors and the team distributes electronically or manually to target responders 20-30 as a pilot. Sometimes they interview patients to assure all the questions clear and understood by the responders. All comments brought for discussion. The correction of the survey was done based on the agreement of most research members. ${ }^{17}$ The research team tested the McDonald's $\omega$ and Cronbach alpha for internal reliability in the pilot responders by using Statistical Package of Social Sciences (SPSS), Statistical Package of Social Sciences-Analysis of Moment Structures (SPSS-Amos) and Jeffrey's Amazing Statistics Program (JASP). ${ }^{18}$

\section{Internal Consistency Reliability}

Item-item Correlation

The method was used to measure each question to another one, with high correlation results in more than 0.7 , that is high internal consistency reliability survey. ${ }^{1,18}$

\section{Item-total Correlation}

The method was used to measure the total questions allocates with each question alone. High results more than 0.7, the high correlate internal consistency reliability of the survey. ${ }^{1,18}$

\section{Split Half Reliability (Gutmann's $\lambda 6$ )}

The method was used through the SPSS and JASP program with the scale option and reliability section for all the questions with scale or ordinal data need to be measured. The test used a split-half option. The SPSS or
JASP will split the question into two half and measure the coloration of the two groups. The high results more than 0.9 of correlation means the high reliability with internal consistency. ${ }^{17,19,20}$

\section{McDonald's $\omega$, Cronbach Alpha}

The research team applied McDonald's $\omega$ and Cronbach alpha for internal reliability by using SPSS and JASP. All the questions with scale or ordinal data included in the analysis. The scale more than 0.9 ; it will be excellent internal consistency, 0.7-0.9 means good reliability, 0.3-0.6 means not acceptable reliability and the score less than 0.3 means weak reliability. ${ }^{17,21,22}$

\section{Face Content Validity}

The principle authors designed the survey and research team revised self-reliantly. Each member revised all the survey content questions based on the updated literature and experience. Any violations had been sent to all research team for further discussion and agreements. The survey had been corrected and agreement from the research team. One of the team members transferred all the surveys to the Arabic language and double-checked by all team members again for content and accurate translation. ${ }^{1,17}$

\section{Construct Validity}

\section{Exploratory Factorial Analysis}

The method was used for the construct validity of the survey. The factor was used univariate description and Kaiser-Myer-Olin measure of sampling adequacy and Bartlett's test sphericity. The extraction used principal components analysis, the Eigen values greater than (1) with the maximum iteration of convergence (25) and display through un-rotated faction solution and scree plot. The rotation used Varimax. ${ }^{15,20}$

\section{Confirmatory Factor Analysis}

The test was done through SPSS-Amos and JASP software programs with factor variances, R-Sequated, fit measurements, factor loading, without emulation, error calculated with CI 95\% and robust method, it was with the auto-estimator and without standardization, it was with pathway analysis. ${ }^{15,20}$

\section{Collinearity}

The test was done through JASP with linear regression for collinearity diagnostics including Eigen value and condition index, the coefficient used with CI 95\% tolerance and variance inflation factor, the model fit through ANOVA and autocorrelation with Durbin-Watson. ${ }^{23}$

\section{Statistical Analysis}

Various biostatical analysis was done in the current study like the McDonald's $\omega$, Cronbach alpha and Gutmann's $\lambda 6$ for calculation reliability. The Kaiser-Meyer-Olkin measure of sampling adequacy and Bartlett's test of sphericity with approximate chi-square for Exploratory Factor Analysis (EFA). The factor variances, R-Sequated, fit measurements, factor loading, without emulation, error calculated with CI 95\% and robust method, it was with the auto-estimator and without standardization, it was with scree plot and pathway analysis. Collinearity had been diagnostician through linear regression the variance inflation factor was calculated, the model fit through ANOVA and auto-correlation with DurbinWatson. All biostatical analysis was done by the Statistical Package of Social Sciences (SPSS), SPSS-AMOS and Jeffrey's Amazing Statistics Program (JASP).

\section{RESULTS}

A total of 209 pharmacists responded. The majority of responders were Saudi 185 (88.52\%). The among responders were males $108(61.77 \%)$ 


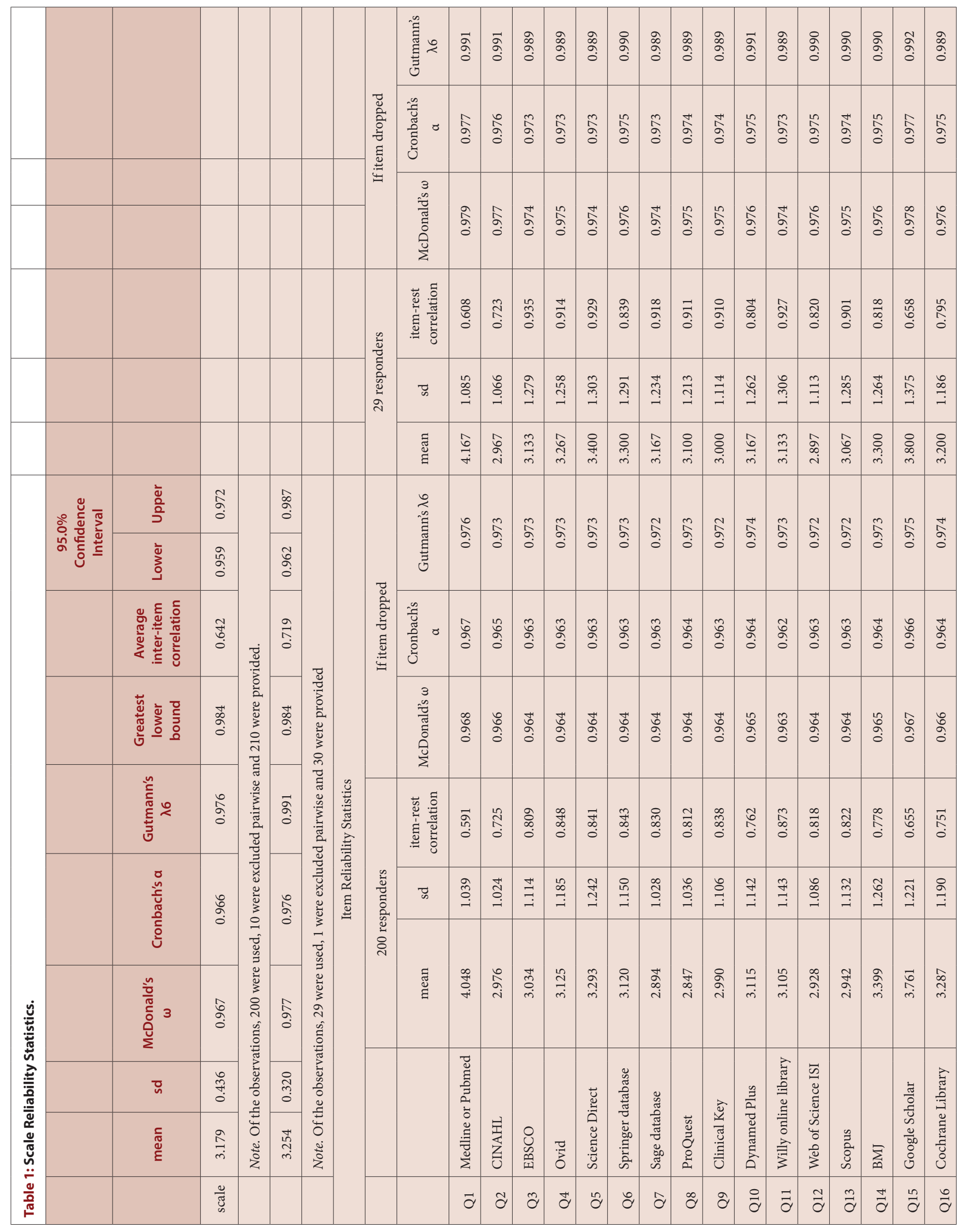


and females 101 (48.33\%). Most of the responders were in age (18-29) years and age (30-44) years were $104(49.67 \%)$ and 78 (37.32\%), respectively. The majority of responders had a doctor of pharmacy and a Bachelor's degree in pharmacy was $92(44.32 \%)$ and 81 (38.94\%), respectively. Most of the pharmacists had not $16(8 \%)$ certified of pharmaceuticals specialties 193 (92\%).

\section{Reliability}

The three tests had been done of reliability with 16 questions for the initial (29) responders mean \pm SD was $3.254 \pm 0.320$ and McDonald's $\omega$, Cronbach alpha and Gutmann's $\lambda 6$ were $0.977,0.976$ and 0.991 , respectively, while inter-item coloration was 0.642 . After the completed number of responders (200), the tests mean \pm SD was $3.179 \pm 0.436$, McDonald's $\omega$, Cronbach alpha and Gutmann's $\lambda 6$ were $0.967,0.966$ and 0.976 , respectively and inter-item coloration was 0.719 among the 30 responders. All the questions of item-total coloration $>0.6$, the McDonald's $\omega$, Cronbach alpha and Gutmann's $\lambda 6$ value if deleted was $>0.97$, while with responders number (200), the item-total coloration $>0.7$, McDonald's $\omega$, Cronbach alpha and Gutmann's $\lambda 6$ value if deleted was $>0.97$ (Table 1). The Split-half reliability of 200 valid cases and 16 items; the Cornbrash's alpha of part 1 was 0.938 , while part 2 was 0.938 , the correlation between forms was 0.924 . The Spearman-Brown Coefficient of equal length was 0.960 and Guttman Split-Half Coefficient was 0.960 (Table 2).

\section{Validity}

By using Exploratory Factor Analysis (EFA), the Kaiser-Meyer-Olkin measure of sampling adequacy was 0.941 and Bartlett's test of sphericity with approximate chi-square was $<0.001$ (Table 2 ). The commonalities extraction for all questions was $>0.58$, the related components were one with the rotated component matrix $>0.59$ of all the 16 questions in component 1 as suggested and discovered by scree plot (Figure 1). They were confirmed by confirmatory with statistically significant $(p<0.001)$ of the factor model, by pathway analysis and fit with the original survey. The confirmatory factor index was 0.862 , Tucker-Lewis Index (TLI) was 0.841, Goodness of fit index (GFI) was 0.906 and Expected cross valida- tion index (ECVI) 3.270. Other results Bentler-Bonett Non-normed Fit Index (NNFI) was 0.841, Bentler-Bonett Normed Fit Index (NFI) was 0.836, Parsimony Normed Fit Index (PNFI) was 0.725, Bollen's Relative Fit Index (RFI) was 0.811, Bollen's Incremental Fit Index (IFI) 0.863, Relative Noncentrality Index (RNI) was 0.862 , Root mean square error of approximation (RMSEA) was 0.148 and Standardized root mean square residual (SRMR) was 0.054 (Table 3 and 4). The square, multiple correlations of the questions R2 were from 0.326 to 0.813 , while factor loading was all the questions $>0.599$ and it was a range $(0.599-1.057)$ with $p<0.001$. In the pathway analysis that's each latent factor and observed coloration with $>0.7$ with $p<0.001$ as explored in pathway analysis (Figure 2).

\section{Collinearity}

The correlation coefficients of 16 questions was R2 (0.901) and RMSE was $(0.376)$ with statistically significant $(p<0.001)$, while the auto-correlation was 0.066 with not statically significant $(p=0.317)$. The majority of the 16 questions had Enjuone value close to number 1, while 3 questions

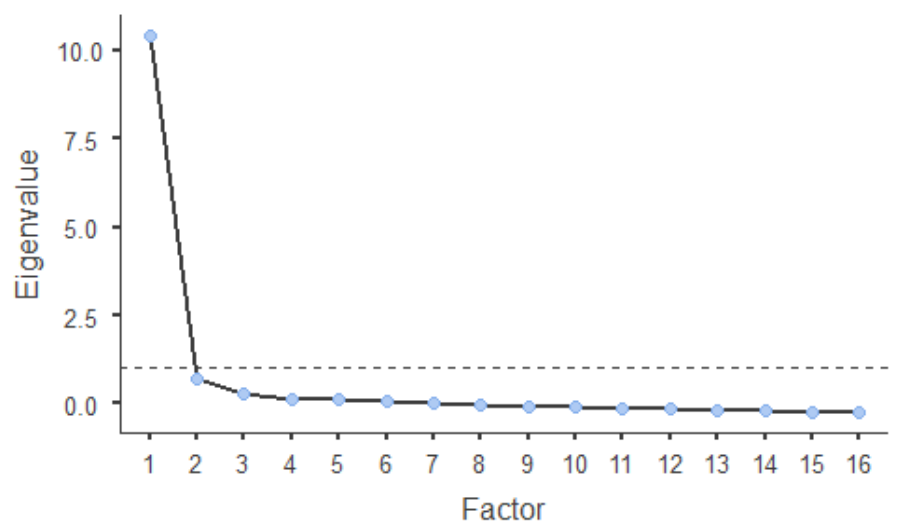

Figure 1: Exploratory Factor Analysis Scree Plot.

\begin{tabular}{|c|c|c|c|c|}
\hline \multicolumn{5}{|c|}{ Case Processing Summary } \\
\hline & & \multicolumn{2}{|c|}{$\mathrm{N}$} & $\%$ \\
\hline \multirow{3}{*}{ Cases } & Valid & \multicolumn{2}{|c|}{200} & 95.2 \\
\hline & Excluded $^{\mathrm{a}}$ & \multicolumn{2}{|c|}{10} & 4.8 \\
\hline & Total & \multicolumn{2}{|c|}{210} & 100.0 \\
\hline \multicolumn{5}{|c|}{ a. Listwise deletion based on all variables in the procedure. } \\
\hline \multicolumn{5}{|c|}{ Reliability Statistics } \\
\hline \multirow{5}{*}{ Cronbach's Alpha } & & \multirow{2}{*}{ Part 1} & Value & .938 \\
\hline & & & $\mathrm{N}$ of Items & $8^{\mathrm{a}}$ \\
\hline & & \multirow{2}{*}{ Part 2} & Value & .936 \\
\hline & & & $\mathrm{N}$ of Items & $8^{\mathrm{b}}$ \\
\hline & & \multicolumn{2}{|c|}{ Total $\mathrm{N}$ of Items } & 16 \\
\hline \multicolumn{4}{|l|}{ Correlation Between Forms } & .924 \\
\hline \multirow{2}{*}{\multicolumn{2}{|c|}{ Spearman-Brown Coefficient }} & \multicolumn{2}{|c|}{ Equal Length } & .960 \\
\hline & & \multicolumn{2}{|c|}{ Unequal Length } & .960 \\
\hline \multicolumn{4}{|l|}{ Guttman Split-Half Coefficient } & .960 \\
\hline \multicolumn{5}{|c|}{ a. The items are: Medline or Pubmed, CINAHL, EBSCO, Ovid, Science Direct, Springer database, Sage database, ProQuest. } \\
\hline \multicolumn{5}{|c|}{$\begin{array}{l}\text { b. The items are: ClinicalKey, Dynamed Plus, Willy online library, Web of Science ISI, Scopus, BMJ, Google Scholar, Cochrane } \\
\text { Library. }\end{array}$} \\
\hline
\end{tabular}




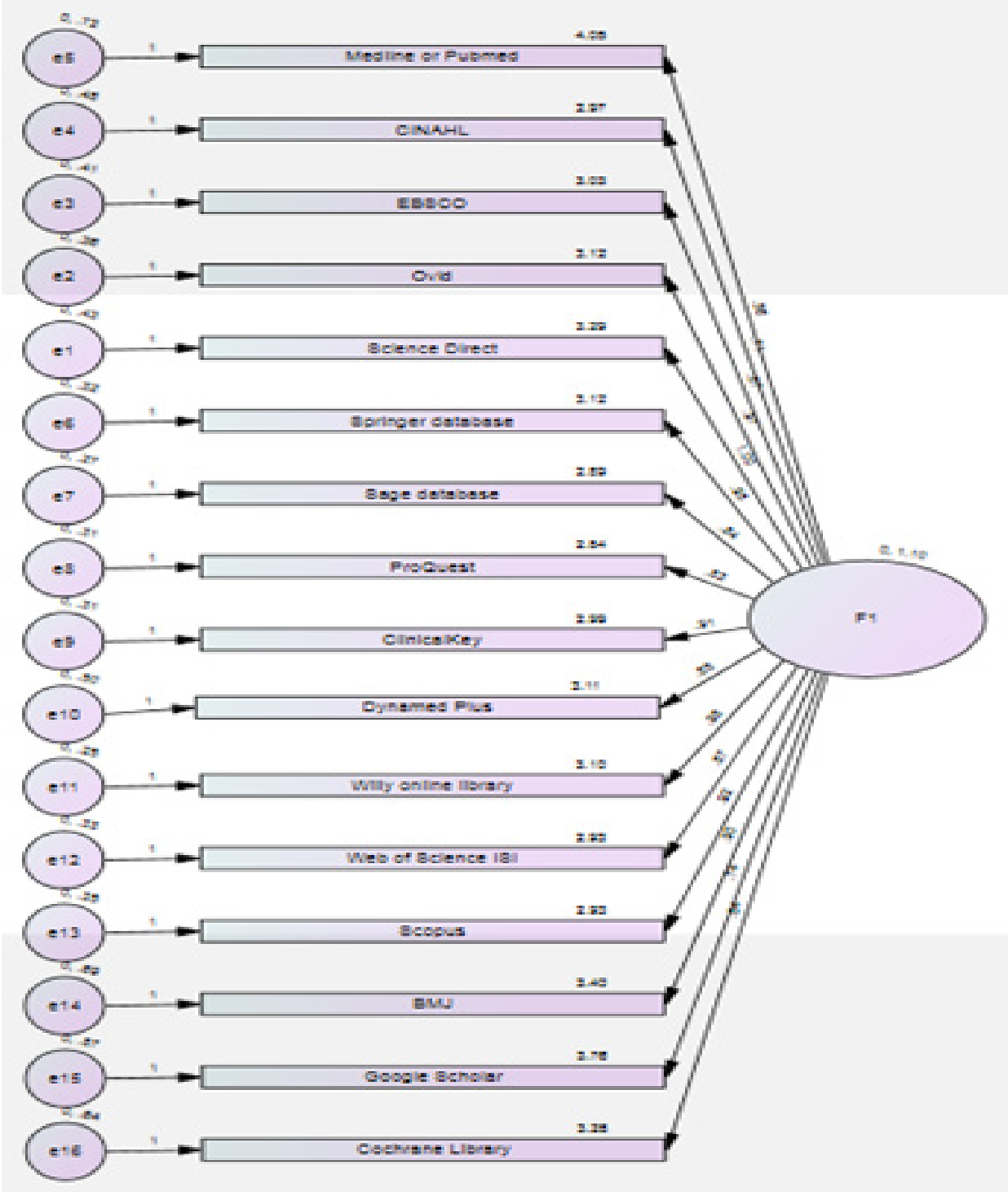

Figure 2: Confirmatory analysis pathway diagram.

\begin{tabular}{|c|c|c|c|c|c|c|c|}
\hline \multirow{2}{*}{\multicolumn{3}{|c|}{$\begin{array}{c}\text { Exploratory Factor Analysis (EFA) } \\
\text { KMO and Bartlett's Test }\end{array}$}} & \multirow[b]{3}{*}{ CFI } & \multicolumn{4}{|c|}{ Confirmatory Factor Analysis (CFA) } \\
\hline & & & & \multirow[b]{2}{*}{0.862} & & & \\
\hline \multicolumn{2}{|c|}{$\begin{array}{l}\text { Kaiser-Meyer-Olkin Measure of Sampling } \\
\text { Adequacy. }\end{array}$} & .941 & & & & & \\
\hline \multirow{3}{*}{ Bartlett's Test of Sphericity } & $\begin{array}{l}\text { Approx. Chi- } \\
\text { Square }\end{array}$ & 3282.416 & Chi-square test & & & & \\
\hline & df & 120 & Baseline model & 3387.385 & \multicolumn{2}{|c|}{120} & $\mathrm{P}$ \\
\hline & Sig. & $<.001$ & Factor model & 554.808 & \multicolumn{2}{|c|}{104} & $<.001$ \\
\hline & Communalities & Factor loading & $\begin{array}{l}\text { Squared Multiple } \\
\text { Correlations }\end{array}$ & $\begin{array}{c}\text { Factor } \\
\text { loading (F1) }\end{array}$ & \multicolumn{2}{|c|}{$\begin{array}{l}\text { 95\% Confidence } \\
\text { Interval }\end{array}$} & \\
\hline \multirow[t]{2}{*}{ Items } & Extraction & Component & $\mathbf{R}^{2}$ & & & & $\mathbf{p}$ \\
\hline & & 1 & & & Lower & Upper & \\
\hline Medline or Pubmed & .768 & 0.594 & 0.326 & 0.599 & 0.484 & 0.714 & $<.001$ \\
\hline CINAHL & .585 & 0.744 & 0.544 & 0.754 & 0.640 & 0.868 & $<.001$ \\
\hline
\end{tabular}




\begin{tabular}{|c|c|c|c|c|c|c|c|}
\hline EBSCO & .714 & 0.831 & 0.681 & 0.923 & 0.818 & 1.028 & $<.001$ \\
\hline Ovid & . .757 & 0.862 & 0.742 & 1.028 & 0.937 & 1.118 & $<.001$ \\
\hline Science Direct & .759 & 0.857 & 0.725 & 1.057 & 0.965 & 1.149 & $<.001$ \\
\hline Springer database & .770 & 0.862 & 0.757 & 1.008 & 0.916 & 1.100 & $<.001$ \\
\hline Sage database & .818 & 0.854 & 0.752 & 0.896 & 0.803 & 0.989 & $<.001$ \\
\hline ProQuest & .792 & 0.840 & 0.723 & 0.887 & 0.786 & 0.989 & $<.001$ \\
\hline ClinicalKey & .786 & 0.858 & 0.749 & 0.964 & 0.865 & 1.064 & $<.001$ \\
\hline Dynamed Plus & .655 & 0.783 & 0.619 & 0.904 & 0.795 & 1.012 & $<.001$ \\
\hline Willy online library & .820 & 0.895 & 0.813 & 1.041 & 0.959 & 1.122 & $<.001$ \\
\hline Web of Science ISI & .762 & 0.839 & 0.716 & 0.919 & 0.811 & 1.027 & $<.001$ \\
\hline Scopus & .751 & 0.842 & 0.728 & 0.974 & 0.877 & 1.071 & $<.001$ \\
\hline BMJ & .800 & 0.786 & 0.579 & 0.967 & 0.863 & 1.071 & $<.001$ \\
\hline Google Scholar & .670 & 0.658 & 0.413 & 0.790 & 0.664 & 0.915 & $<.001$ \\
\hline Cochrane Library & .704 & 0.757 & 0.546 & 0.888 & 0.771 & 1.005 & $<.001$ \\
\hline \multicolumn{8}{|c|}{$\begin{array}{l}\text { Extraction Method: Principal Component Analysis. } \\
\text { Rotation Method: Varimax with Kaiser Normalization. }\end{array}$} \\
\hline
\end{tabular}

\begin{tabular}{|c|c|c|}
\hline Index & Value & $\begin{array}{l}\text { normal } \\
\text { value }\end{array}$ \\
\hline Comparative Fit Index (CFI) & 0.862 & $>0.9$ \\
\hline Tucker-Lewis Index (TLI) & 0.841 & $>0.9$ \\
\hline $\begin{array}{l}\text { Bentler-Bonett Non-normed Fit Index } \\
\text { (NNFI) }\end{array}$ & 0.841 & $>0.9$ \\
\hline Bentler-Bonett Normed Fit Index (NFI) & 0.836 & $>0.9$ \\
\hline Parsimony Normed Fit Index (PNFI) & 0.725 & $>0.9$ \\
\hline Bollen's Relative Fit Index (RFI) & 0.811 & $>0.9$ \\
\hline Bollen's Incremental Fit Index (IFI) & 0.863 & $>0.9$ \\
\hline Relative Noncentrality Index (RNI) & 0.862 & $>0.9$ \\
\hline $\begin{array}{l}\text { Root mean square error of approxima- } \\
\text { tion (RMSEA) }\end{array}$ & $\begin{array}{c}0.148 \\
\text { CI } 90 \%(0.163-0.160) \\
\mathrm{P}<0.001\end{array}$ & $>$ or $=0.08$ \\
\hline $\begin{array}{l}\text { Standardized root mean square residual } \\
\text { (SRMR) }\end{array}$ & 0.054 & $>0.04$ \\
\hline Hoelter's critical N ( $\alpha=.05)$ & 47.200 & \\
\hline Hoelter's critical N ( $\alpha=.01)$ & 51.380 & \\
\hline Goodness of fit index (GFI) & 0.906 & $>0.9$ \\
\hline McDonald fit index (MFI) & 0.322 & \\
\hline Expected cross validation index (ECVI) & 3.270 & $<5$ \\
\hline
\end{tabular}

only had condition index more than 30 . All of the 16 questions had the Variance inflation factor (VIF) less than 10 and had tolerance more than 0.1 (Table 5)

\section{DISCUSSION}

The evidence-based medicine was playing a noteworthy role in pharmacy practice. ${ }^{2}$ The pharmacist utilized evidence-based medicine during drug information resources and pharmacy research. ${ }^{24}$ The authors and his colleagues conducted the study of pharmacists' knowledge about evidence-based medicine references in pharmacy research. The study was a cross-sectional survey distributed to the pharmacists. The author did some tools of reliability and validity briefly. ${ }^{4}$ However, the details of reliability or validity for the survey of the knowledge of EBM resources used in pharmacy research had been done in the current study. The results showed in the pilot study of 30 responders with three different reliability tests was excellent and once repeated with completed responders, was also excellent with exceedingly more 0.97 . The inter-item correlation or item-total coloration was right in the primary pilot responders and completed responders means the question of internal consistency was high reliable. The findings of the validity test showed a good sample size for exploratory factor analysis. The EFA recommends one factor with 16 questions with proper extraction and rotated component matrix. It's confirmed by CFA with one factor with statistical significance through a regression model, scree plot and pathway analysis. The findings showed that there is no collinearity with all the 16 questions except three-question might affect the validity of the survey. However, by increasing the number of responders will remove all collinearity related issues. The survey of knowledge about EBM resources used for pharmacy research was high reliability and validity. This is the first investigation that was done in the Kingdom of Saudi Arabia or the Gulf and Middle East countries.

\section{CONCLUSION}

The assessment of pharmacist knowledge with evidence-based medicine resources used in pharmacy research with a specific survey distributed in the Kingdom of Saudi Arabia. It was done through the reliability of 


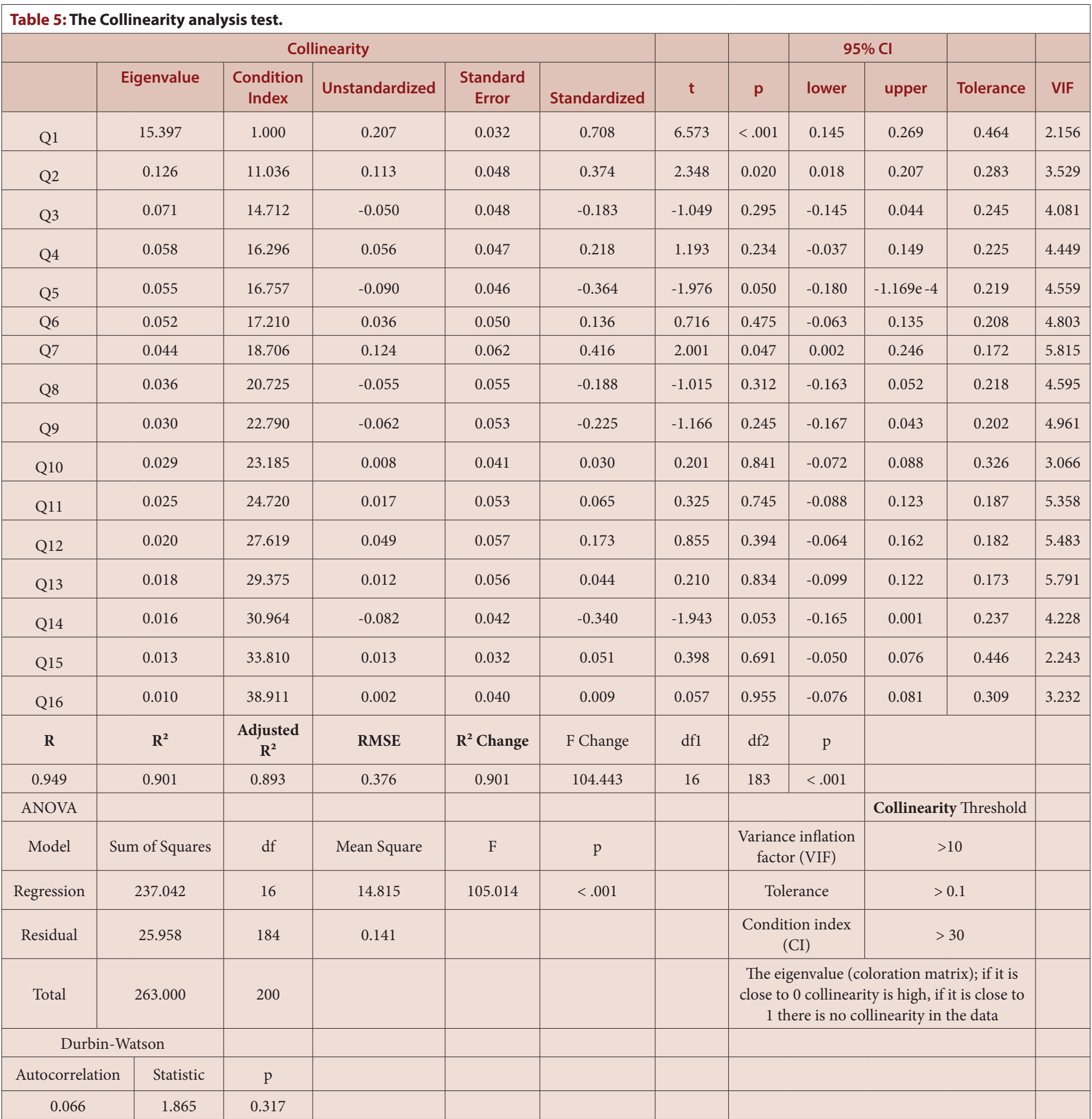

internal consistency through several bio-statistical tests. Besides, the survey had high content and constructed validity by various testes when repeated, used it in the future. The survey needs an appropriate sample size in further research in Saudi Arabia.

\section{ACKNOWLEDGEMENT}

None.

\section{CONFLICT OF INTEREST}

The authors declare no conflict of interest.

\section{ABBREVIATIONS}

KSA: Kingdom of Saudi Arabia; CFI: Comparative Fit Index; TLI: Tucker-Lewis Index; NNFI: Bentler-Bonett Non-normed Fit Index; NFI: Bentler-Bonett Normed Fit Index; PNFI: Parsimony Normed Fit Index; RFI: Bollen's Relative Fit Index; IFI: Bollen's Incremental Fit Index; RNI: Relative Noncentrality Index; RMSEA: Root Mean Square Error of Approximation; SRMR: Standardized Root Mean Square Residual; GFI: Goodness of Fit Index; MFI: McDonald Fit Index; ECVI: Expected Cross Validation index; SPSS: Statistical Package of Social Sciences; JASP: Jeffrey's Amazing Statistics Program; ANOVA: Analysis of 
Variance; SPSS-Amos: Statistical Package of Social Sciences-Analysis of Moment Structures.

\section{REFERENCES}

1. Kumar R. Research methodology a step-by-step guide for beginners. $3^{\text {rd }}$ edition. SAGE Publications Ltd., 2011.

2. Al-Quteimat OM, Amer AM. Evidence-based pharmaceutical care: The next chapter in pharmacy practice. Saudi Pharm J. 2016;24(4):447-51.

3. Mariano AS, Souza NM, Cavaco A, et al. Healthcare professionals' behavior, skills, knowledge and attitudes on evidence-based health practice: A protocol of cross-sectional study. BMJ Open. 2018;8(6):1-5

4. AlomiYA, Altebainawi $A F$, Alabdullatif $A$, et al. Evidence based medicine resources knowledge used in pharmacy research in the Kingdom of Saudi Arabia. In: ISPOR Europe. 2019. Cited 2019 Dec 10. Available from: https://www.ispor.org/ heor-resources/presentations-database/presentation/euro2019-3118/93718.

5. Cailor SM, Chen AMH, Kiersma ME, et al. The impact of a research course on pharmacy students' perceptions of research and evidence-based practice. Curr Pharm Teach Learn. 2017;9(1):28-36.

6. Bahmaid RA, Karim M, Al-Ghamdi N, et al. Impact of research educational intervention on knowledge, attitudes, perceptions and pharmacy practices towards evidence-based medicine among junior pharmacists. Cureus. 2018;10(6):1-18.

7. Mccoll A, Smith $H$, White $P$, et al. General practitioners' perceptions of the route to evidence-based medicine: a questionnaire survey. BMJ. 1998;316:361-5

8. Abu FR, Alefishat E, Suyagh M, et al. Evidence-based medicine use in pharmacy practice: A cross-sectional survey. J Eval Clin Pract. 2014;20(6):786-92.

9. Buabbas AJ, Alsaleh FM, Al-Shawaf HM, et al. The readiness of hospital pharmacists in Kuwait to practise evidence-based medicine: A cross-sectiona study. BMC Med Inform Decis Mak. 2018;18(1):1-13.

10. Ahmad ASH, Al-Mutar NBE, Al-Hulabi FAS, et al. Evidence-based practice among primary care physicians in Kuwait. J Eval Clin Pract. 2009;15(6):1125-30.

11. Ashri N, Al-Amro H, Hamadah L, et al. Dental and medical practitioners' awareness and attitude toward evidence based practice in Riyadh, Saudi Arabia: A comparative study. Saudi J Dent Res. 2014;5(2):109-16.

12. Al-Jazairi AS, Alharbi R. Assessment of evidence-based practice among hospital pharmacists in Saudi Arabia: attitude, awareness and practice. Int J Clin Pharm. 2017;39(4):712-21

13. Boynton PM, GreenhalghT. Hands-on guide to questionnaire research: selecting, designing and developing your questionnaire. Br Med J. 2004;328(7451):13125

14. Artino AR, LaRochelle JS, Dezee KJ, et al. Developing questionnaires for educational research: AMEE Guide No. 87. Med Teach. 2014;36(6):463-74.

15. Mackenzie SB, Podsakoff PM, Podsakoff NP, et al. Construct measurement and validation procedures in mis and behavioral research: integrating new and existing techniques. MIS Q. 2011;35(2):293-334.

16. Siny T, Colin FR, Abdullah ST. Avoiding failed spinal anesthesia: "Advik technique" A very rare unusual site of ventilator breathing circuit leakage: Beware. Saudi J Anesth. 2017:11(5):80-9.

17. Jain S, Dubey S, Jain S. Designing and validation of questionnaire. Int Dent Med J Adv Res. 2016;2(1):1-3.

18. Kimberlin $C L$, Winterstein AG. Validity and reliability of measurement instruments used in research. Am J Heal Pharm. 2008;65(23):2276-84.

19. Nath S. Best split-half and maximum reliability. IOSR J Res Method Educ. 2013;3(1):01-8.

20. Hervás A, Guàrdia Olmos J, Peró $\mathrm{CM}$, et al. A structural equation model for analysis of factors associated with the choice of engineering degrees in a technical university. Abstr Appl Anal. 2013;2013.

21. Viladrich $C$, Angulo-Brunet A, Doval E. A journey around alpha and omega to estimate internal consistency reliability. An Psicol. 2017;33(3):755-82.

22. Deng $L$, Chan $W$. Testing the difference between reliability coefficients alpha and omega. Educ Psychol Meas. 2017;77(2):185-203.

23. Dormann CF, Elith J, Bacher $S$, et al. Collinearity: A review of methods to deal with it and a simulation study evaluating their performance. Ecography. 2013;36(1):027-46.

24. Alomi YA, Almudaiheem HY, Alsharari A. National survey of drug information centers practice in saudi arabia: evidence based medicine-therapeutics guidelines system (Ebm-Tg) at Moh. Value Heal. 2016;19(7):A496. 